\title{
Method for Controlling Intracellular Protein Activity Using Photoresponsive Nanoparticles
}

\author{
Shuhei Murayama, ${ }^{1}$ Noriaki Kono, ${ }^{1}$ Takashi Takaki, ${ }^{2}$ and Masaru Kato ${ }^{1 *}$ \\ ${ }^{1}$ Division of Bioanalytical Chemistry, School of Pharmacy, Showa University, \\ 1-5-8 Hatanodai, Shinagawa-ku, Tokyo 142-8555, Japan \\ ${ }^{2}$ Division of Electron Microscopy, Showa University, 1-5-8 Hatanodai, Shinagawa-ku, Tokyo 142-8555, Japan
}

(Received August 11, 2021; accepted October 12, 2021; online published October 27, 2021)

Keywords: photoresponsive nanoparticles, gel mesh structure, encapsulated proteins, controlled release, protein function control

Protein levels in cells can be controlled by delivering and releasing the target protein to a cell. Herein, we report the preparation of photoresponsive nanoparticles with different protein loadings for application as protein delivery vehicles. The nanoparticles were prepared by radical polymerization using an X-shaped photoresponsive linker $\left(M_{w}=2000\right)$ and a cationic linker. The incorporation of a fluorescent polysaccharide (FITC-Dex) or protein (caspase 3) into the nanoparticles did not create significant differences in the physical properties of the resultant nanoparticles; they were $\sim 150 \mathrm{~nm}$ in size with weak positive zeta potentials. These new photoresponsive nanoparticles can encapsulate and release various protein-containing compounds with different molecular weights (3-250 kDa). In addition, the amount of compound released from the nanoparticles can be tailored by altering the amount of compound encapsulated in the nanoparticles. In this study, nanoparticles containing cationic units were introduced into cells via endocytosis. We controlled the activity of the nanoparticle-released proteins within HeLa cells. Specifically, adjusting the protein loading in the nanoparticles enabled control over the activity of the proteins released into the cell, and thus the level of protein function, which provides a powerful tool for elucidating the functions of proteins.

\section{Introduction}

Physiological processes and their activities are regulated by protein functions and expression levels. Non-invasive and accurate methods of controlling the amounts and functions of proteins expressed in cells can facilitate the elucidation of their cellular functions and investigations of the causes of diseases. This can collectively lead to new treatment methods. Protein expression within a cell is balanced and optimized for cellular function, with a feedback function intervening to stop gene and protein overexpression. ${ }^{(1-3)}$ Consequently, it is difficult to accurately control the level of protein expression in a cell. More detailed and accurate quantitative control over protein levels becomes possible by delivering a target protein into a cell. Various researchers have attempted to accurately control the quantities of cell-functioning proteins; however, this

*Corresponding author: e-mail: masaru-kato@umin.ac.jp https://doi.org/10.18494/SAM.2022.3585 
research remains incomplete due to poor versatility and insufficient control over the amount, timing, and location of protein release. ${ }^{(4-7)}$

We previously developed a versatile, non-invasive method for controlling the functions of various proteins based on external light signals and a gel prepared from an X-shaped photocleavable crosslinker. We refer to this method as "protein activation and release from cage by external light" (PARCEL) by imagining compounds delivered in parcels. ${ }^{(8)}$ Previous studies showed that such hydrogel-type nanoparticle-encapsulated proteins are stable. ${ }^{(9)}$ The weak cationic hydrogel-type nanoparticle-encapsulated proteins were attracted to the surface of cell membranes and then introduced into these cells by endocytosis; once inside the cell, they were activated by external UV stimulation to release the protein from the nanoparticles. Thus, we successfully controlled the protein activity within cells in a spatiotemporal manner. ${ }^{(9-11)}$

There are three strategies for controlling the amount of a functional compound released into a cell using such nanoparticles: (1) changing the intensity of the external stimulus, (2) changing the number of nanoparticles introduced into the cell, and (3) changing the protein dosing of the nanoparticles. By combining these strategies, we expect to achieve spatiotemporal control as well as fine quantitative control over protein activity.

We controlled the release in previous studies using two of these methods: by changing the intensity of the light signal ${ }^{(8)}$ and by controlling the number of nanoparticles introduced into the cell. ${ }^{(12)}$ Both these methods enabled facile control over the activity of the released proteins, but each had disadvantages. Specifically, in the first method, UV light also induced cell damage, and in the second, the number of nanoparticles affected the efficiency of introducing nanoparticles into the cell. Hence, to control the activity of released proteins more accurately without affecting the temperature or number of nanoparticles within the cells, we developed photoresponsive nanoparticles that contain different amounts of encapsulated proteins. The protein activity was regulated by tailoring the amount of encapsulated proteins in the nanoparticles, which, in turn, affected the release amount, thereby controlling the protein activity in the cell. By observing the change in cellular response after protein release, we found that the amount of intracellular proteins changed the time to cell death.

\section{Materials and Methods}

\subsection{Materials}

Tetra(poly(ethyl glycol))amine (SUNBRIGHT PTE-050PA; $M_{n}, 5328 \mathrm{~g} / \mathrm{mol}$ ) was purchased from NOF Corporation (Tokyo, Japan). Hydrogen peroxide, $N, N, N^{\prime}, N^{\prime}$-tetramethylethylenediamine (TEMED), triethylamine (TEA), acryloyl chloride (AC), acrylamide (AAm), ammonium persulfate (APS), methanol, diethyl ether, sodium chloride, 4-(4,6-dimethoxy-1,3,5-triazin-2-yl)4-methylmorpholinium chloride $n$-hydrate (DMT-MM), chlorpromazine, and (+/-)-dithiothreitol (DTT) were purchased from FUJIFILM Wako Pure Chemical Corporation (Osaka, Japan). Propidium iodide (PI) solution was purchased from Dojindo (Kumamoto, Japan). Amiloride was purchased from Tokyo Chemical Industry (Tokyo, Japan). Caspase 3, $\mathrm{N}$-acetyl-Asp-Glu-ValAsp-7-amido-4-trifluoromethylcoumarin (Ac-DEVD-AFC), fluorescein isothiocyanate- 
dextrans (FITC-Dexs), and methyl- $\beta$-cyclodextrin were purchased from Sigma-Aldrich (St. Louis, MO). Dulbecco's modified Eagle medium (DMEM) and phosphate buffered salts (PBS) were purchased from Thermo Fisher Scientific (Waltham, MA). Water was purified with a Milli-Q system (Millipore, Bedford, MA).

\subsection{X-shaped photocleavable crosslinker, X-shaped non-cleavable crosslinker, and cationic linker}

A photocleavable linker (PEG-Photo-AC), non-cleavable crosslinker (PEG-AC), and cationic linker (DAB-Ac) were synthesized as described previously. ${ }^{(8,9,13)}$

\subsection{Preparation of photodegradable nanoparticles with FITC-Dexs}

First, $30 \mu \mathrm{L}$ of a $50 \mathrm{mg} / \mathrm{mL}$ solution of PEG-AC, $30 \mu \mathrm{L}$ of a $50 \mathrm{mg} / \mathrm{mL}$ solution of PEGPhoto-AC, $50 \mu \mathrm{L}$ of DAB-Ac, $50 \mu \mathrm{L}$ of $2.0 \mathrm{mg} / \mathrm{mL}$ FITC-Dex $(3,10,20,40,70$, or $250 \mathrm{kDa})$, and $240 \mu \mathrm{L}$ of pure water were added to a microtube and shaken for $5 \mathrm{~s}$. Subsequently, $50 \mu \mathrm{L}$ of $0.1 \mathrm{~mol} / \mathrm{L}$ APS and $50 \mu \mathrm{L}$ of $0.1 \mathrm{~mol} / \mathrm{L}$ TEMED were added to the mixture to induce radical gelation at room temperature. The mixture was vortexed for $20 \mathrm{~min}$ to prepare nanoparticles with a diameter of $150 \mathrm{~nm}$. The nanoparticles were collected using a Vivaspin 6 MWCO 30,000 polyethersulfone (PES) centrifugal concentrator filtration system (Sartorius, Germany).

\subsection{Preparation of photoresponsive nanoparticles with enzymes}

First, $30 \mu \mathrm{L}$ of a $50 \mathrm{mg} / \mathrm{mL}$ solution of PEG-AC, $30 \mu \mathrm{L}$ of a $50 \mathrm{mg} / \mathrm{mL}$ solution of PEGPhoto-AC, $50 \mu \mathrm{L}$ of DAB-Ac, $50 \mu \mathrm{L}$ of the enzyme $\left(0.50\right.$ or 0.050 munit $/ \mathrm{mL}^{(14)}$ caspase 3,40 , 4.0 , or $0.40 \mathrm{munit} / \mathrm{mL}$ elastase, or 400,40 , or $4.0 \mathrm{munit} / \mathrm{mL}$ chymotrypsin), and $240 \mu \mathrm{L}$ of pure water were added to a microtube and shaken for $5 \mathrm{~s}$. Subsequently, $50 \mu \mathrm{L}$ of $0.1 \mathrm{~mol} / \mathrm{L}$ APS and $50 \mu \mathrm{L}$ of $0.1 \mathrm{~mol} / \mathrm{L}$ TEMED were added to the mixture to induce radical gelation at room temperature. The mixture was vortexed for $20 \mathrm{~min}$ to prepare nanoparticles with a diameter of $150 \mathrm{~nm}$. The nanoparticles were collected using a Vivaspin 6 filtration system. Finally, we obtained eight types of nanoparticles with enzymes (final concentrations of caspase 3: 0.010 and 0.10 munit $/ \mathrm{mL}$; final concentrations of elastase: $0.080,0.80$, and 8.0 munit $/ \mathrm{mL}$; final concentrations of chymotrypsin: $0.80,8.0$, and $80.0 \mathrm{munit} / \mathrm{mL}$ ).

\subsection{Nanoparticle size distribution, concentration, and zeta potential measurements}

After washing, the nanoparticle solutions were diluted 200 times with $0.1 \mathrm{~mol} / \mathrm{L}$ sodium chloride for loading into a nanoparticle-tracking video microscope (ZetaView, MicrotracBEL, Osaka, Japan). The laser light scattered by the nanoparticles was recorded using a camera attached to the ZetaView microscope. The diffusion coefficient and electrophoretic mobility were determined computationally from the movement of the scattered light. Nanoparticle size was calculated from the diffusion coefficient using the Stokes-Einstein equation, nanoparticle 
surface charge was calculated from the electrophoretic mobility using the Smoluchowski coagulation equation, and nanoparticle concentration was calculated from the total number of particles in the camera field of view with known capacitance using the ZetaView 8.04.02 SP1 software.

\subsection{Nanoparticle size measured by TEM}

The size of the nanoparticles was examined by TEM (H-7600, Hitachi Ltd., Japan) using a negative stain ( $2 \%$ uranyl acetate).

\subsection{In vitro study of amounts of FITC-Dex loaded in and released from nanoparticles}

A $100 \mu \mathrm{L}$ aliquot of the FITC-Dex-loaded particle solution was added to a well of a 96-well plate. The intensity of the signal $\left(\lambda_{e x}=494 \mathrm{~nm}, \lambda_{e m}=518 \mathrm{~nm}\right)$ from the FITC encapsulated in the particles was measured using a multiplate reader (SH-6000, Corona, Japan). Also, a $400 \mu \mathrm{L}$ FITC-Dex-loaded particle solution was irradiated with UV light (Aicure UV20, Panasonic, Osaka, Japan) for $20 \mathrm{~s}\left(0.25 \mathrm{~W} / \mathrm{cm}^{2}\right)$ and subsequently washed using a Vivaspin 6 MWCO 30000 PES centrifugal concentrator filtration system; furthermore, since the nanoparticles were in the upper layer with a small amount of water, more water was added to adjust the nanoparticle concentration before washing. Consequently, a $400 \mu \mathrm{L}$ nanoparticle solution was obtained. Then, $100 \mu \mathrm{L}$ of this irradiated solution was supplied to a well of a 96-well plate to measure the released FITC-Dex. The intensity of the signal $\left(\lambda_{e x}=494 \mathrm{~nm}, \lambda_{e m}=518 \mathrm{~nm}\right)$ from the FITC encapsulated in the particles was measured using a multiplate reader. The FITC-Dex concentrations were calculated using the calibration curves plotted with different amounts of FITC-Dex $(4-125 \mu \mathrm{g})$.

\subsection{Measuring in vitro-released chymotrypsin and elastase activity by fluorescence spectroscopy}

The activity of released chymotrypsin and elastase was measured using borondipyrromethene (BODIPY)-casein, which is a substrate used in protease fluorescence assays. A $100 \mu \mathrm{L}$ aliquot of the protease containing a nanoparticle solution and $100 \mu \mathrm{L}$ of the substrate (BODIPY-casein) were added to a 96-well plate. After UV irradiation $(\lambda=365 \mathrm{~nm})$ for $20 \mathrm{~s}$ $\left(0.25 \mathrm{~W} / \mathrm{cm}^{2}\right)$, the plate was incubated at $37{ }^{\circ} \mathrm{C}$ for $1.5 \mathrm{~h}$, and the fluorescence intensity $\left(\lambda_{e x}=480 \mathrm{~nm}, \lambda_{e m}=530 \mathrm{~nm}\right)$ was measured using a multiplate reader. The enzyme concentrations were determined using calibration curves plotted with different amounts of chymotrypsin $(0.3-2.5 \mu$ unit) or elastase $(0.3-2.5 \mu$ unit).

\subsection{Measuring in vitro-released caspase 3 activity by fluorescence spectroscopy}

The released caspase 3 activity was measured using Ac-DEVD-AFC, which is a substrate used in caspase 3 fluorescence assays. A $100 \mu \mathrm{L}$ aliquot of the protein nanoparticle solution, 
$10 \mu \mathrm{L}$ of the substrate, $5 \mu \mathrm{L}$ DTT, and $85 \mu \mathrm{L}$ PBS were added to a 96-well plate. After UV irradiation $(\lambda=365 \mathrm{~nm})$ for $20 \mathrm{~s}\left(0.25 \mathrm{~W} / \mathrm{cm}^{2}\right)$, the plate was incubated at $37^{\circ} \mathrm{C}$ for $1.5 \mathrm{~h}$, and the fluorescence intensity $\left(\lambda_{e x}=400 \mathrm{~nm}, \lambda_{e m}=485 \mathrm{~nm}\right)$ was measured using a multiplate reader. This UV irradiation condition is not the main cause of the lower caspase 3 activity (Fig. S1). The caspase 3 concentrations were calculated using calibration curves plotted with different amounts of caspase 3 (0.04-5.0 $\mu$ unit).

\subsection{Confirming nanoparticle internalization in cells by endocytosis}

The day before assaying, $200 \mu \mathrm{L}$ of 10 -fold-diluted confluent HeLa cells in DMEM with serum and $2.0 \mathrm{~mL}$ of DMEM with serum were seeded at $37^{\circ} \mathrm{C}$ in a $35 \mathrm{~mm}$ glass-bottom dish. After overnight incubation, the dish was washed with DMEM without serum and $2.0 \mathrm{~mL}$ of DMEM was added. Subsequently, $500 \mu \mathrm{L}$ of an endocytosis inhibitor $(22.3 \mathrm{mg} / \mathrm{mL}$ chlorpromazine, $13 \mathrm{mg} / \mathrm{mL}$ methyl- $\beta$-cyclodextrin, or $0.8 \mathrm{mg} / \mathrm{mL}$ amiloride) was added to the culture dish, followed by incubation for $1 \mathrm{~h}$. A $50 \mu \mathrm{L}$ aliquot of the $20 \mathrm{kDa}$ FITC-Dex-containing nanoparticle solution [(1.5-3.0) $\times 10^{9}$ nanoparticles $\left./ \mathrm{mL}\right]$ was added dropwise into the dish and it was allowed to stand for $20 \mathrm{~min}$ at room temperature. The cell dish was washed three times with $2.0 \mathrm{~mL}$ of DMEM without serum to remove the nanoparticles not introduced into the cells. Finally, $2.0 \mathrm{~mL}$ of DMEM without serum was added, and the nanoparticles were observed with an Fv10i microscope $\left(\lambda_{e x}=494 \mathrm{~nm}, \lambda_{e m}=518 \mathrm{~nm}\right.$, OLYMPUS, Japan).

\subsection{Internalizing nanoparticle-loaded caspase 3 in cells}

The day before assaying, $200 \mu \mathrm{L}$ of 10-fold-diluted confluent HeLa cells in DMEM with serum and $2.0 \mathrm{~mL}$ of DMEM with serum were seeded at $37^{\circ} \mathrm{C}$ in a $35 \mathrm{~mm}$ glass-bottom dish. After overnight incubation, a $50 \mu \mathrm{L}$ aliquot of the nanoparticle-loaded caspase 3 solution was added dropwise into the dish and it was allowed to stand for $20 \mathrm{~min}$ at room temperature. The cell dish was washed three times with $2.0 \mathrm{~mL}$ of DMEM without serum to remove the nanoparticles not introduced into the cells. Finally, $2.0 \mathrm{~mL}$ of DMEM without serum was added.

\subsection{UV irradiation and microscopy}

The cells were irradiated with UV light (Aicure UV20, Panasonic, Osaka, Japan) for $20 \mathrm{~s}$ $\left(0.25 \mathrm{~W} / \mathrm{cm}^{2}\right)$, then examined by microscopy (IX71, OLYMPUS, Japan).

\subsection{Amount of cell death measured using PI solution}

A day before assaying, $100 \mu \mathrm{L}$ of 10 -fold-diluted confluent HeLa cells in DMEM with serum and $2.0 \mathrm{~mL}$ of DMEM with serum were seeded at $37{ }^{\circ} \mathrm{C}$ in a 96 -well plate. After overnight incubation, the well was washed with $100 \mu \mathrm{L}$ of PBS; subsequently, $100 \mu \mathrm{L}$ of DMEM and a 10 $\mu \mathrm{L}$ aliquot of the nanoparticle-loaded caspase 3 solution were added dropwise to the well, and it was allowed to stand for $20 \mathrm{~min}$ at room temperature. The well with cells was washed with 100 
$\mu \mathrm{L}$ of PBS, and subsequently, $100 \mu \mathrm{L}$ of DMEM was added. The cells were irradiated with UV light (Aicure UV20, Panasonic, Osaka, Japan) for $20 \mathrm{~s}\left(0.25 \mathrm{~W} / \mathrm{cm}^{2}\right)$. After $30 \mathrm{~min}$ of incubation, $50 \mu \mathrm{L}$ of PI solution was added and allowed to stand for 15 min to stain the dead cells. Subsequently, the wells were washed three times with $100 \mu \mathrm{L}$ of PBS. The fluorescence intensity $\left(\lambda_{e x}=538 \mathrm{~nm}, \lambda_{e m}=617 \mathrm{~nm}\right)$ was measured using a multiplate reader.

\section{Results and Discussion}

\subsection{Nanoparticle preparation and physical properties}

We prepared nanoparticles by radical polymerization using X-linker $\left(M_{w}=2000\right)$ and cationic linker molecules. ${ }^{(9)}$ As model compounds, we included the same amount of fluorescent polysaccharide (FITC-Dex, 3 or $10 \mathrm{kDa}, 2.0 \mathrm{mg} / \mathrm{mL}$ each) or protein (caspase 3, 0.25, 2.5, or 25 $\mu$ unit) in the nanoparticles. The differences in the physical properties of the resultant nanoparticles, which were examined by the particle-tracking analysis method, were found to be insignificant for introducing nanoparticles into cells (Table 1, Figs. S2 and S3). Irrespective of the size, type, or loading of the encapsulated compound, the nanoparticles were approximately $150 \mathrm{~nm}$ in size with weak positive zeta potentials (less than $20 \mathrm{mV}$ ), ${ }^{(15)}$ which suggests that the compounds are captured stochastically by generating a mesh structure in the gel. By controlling the amount of substance present during the radical polymerization, the amount of compound encapsulated into the nanoparticles can be controlled. We hypothesize that the amount of compound released can be tailored by controlling the loading of encapsulated compounds. To demonstrate that quantitative control can be achieved, the amounts of model compounds present during preparation, contained in the nanoparticles, and released via light activation were evaluated using fluorescence-modified polysaccharides (FITC-Dex) as models.

\subsection{Effect of molecular weight on amounts of encapsulated and released compounds}

To identify the effect of the molecular weights of the encapsulated compounds on encapsulation and release, FITC-Dex with various molecular weights $(3-250 \mathrm{kDa})$ was encapsulated in the photoresponsive nanoparticles, followed by UV irradiation to release the compounds (Fig. S4). The amounts of encapsulated and released FITC-Dex were determined from the FITC signal intensity $\left(\lambda_{e x}=494 \mathrm{~nm}, \lambda_{e m}=518 \mathrm{~nm}\right)$. The results are shown in Fig. 1.

Table 1

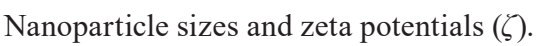

\begin{tabular}{lccc}
\hline Compound & Loading amount & Particle size $(\mathrm{nm})$ & $\zeta(\mathrm{mV})$ \\
\hline FITC-Dex: $3 \mathrm{kDa}$ & $0.10 \mathrm{mg}$ & 132 & $10.40 \pm 0.08$ \\
FITC-Dex: $10 \mathrm{kDa}$ & $0.10 \mathrm{mg}$ & 143 & $4.27 \pm 0.19$ \\
Caspase 3 & $0.25 \mu \mathrm{unit}$ & 151 & $4.25 \pm 0.17$ \\
Caspase 3 & $2.5 \mu \mathrm{unit}$ & 143 & $1.36 \pm 0.06$ \\
Caspase 3 & $25 \mu \mathrm{unit}$ & 144 & $8.30 \pm 0.72$ \\
\hline
\end{tabular}




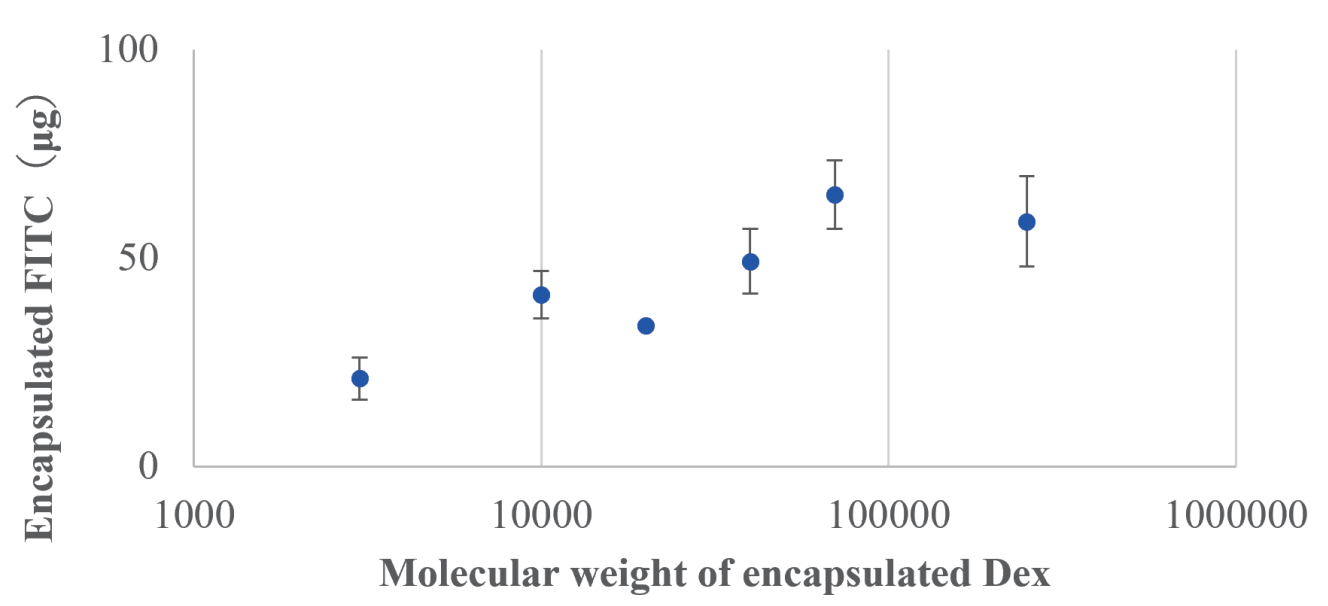

(a)

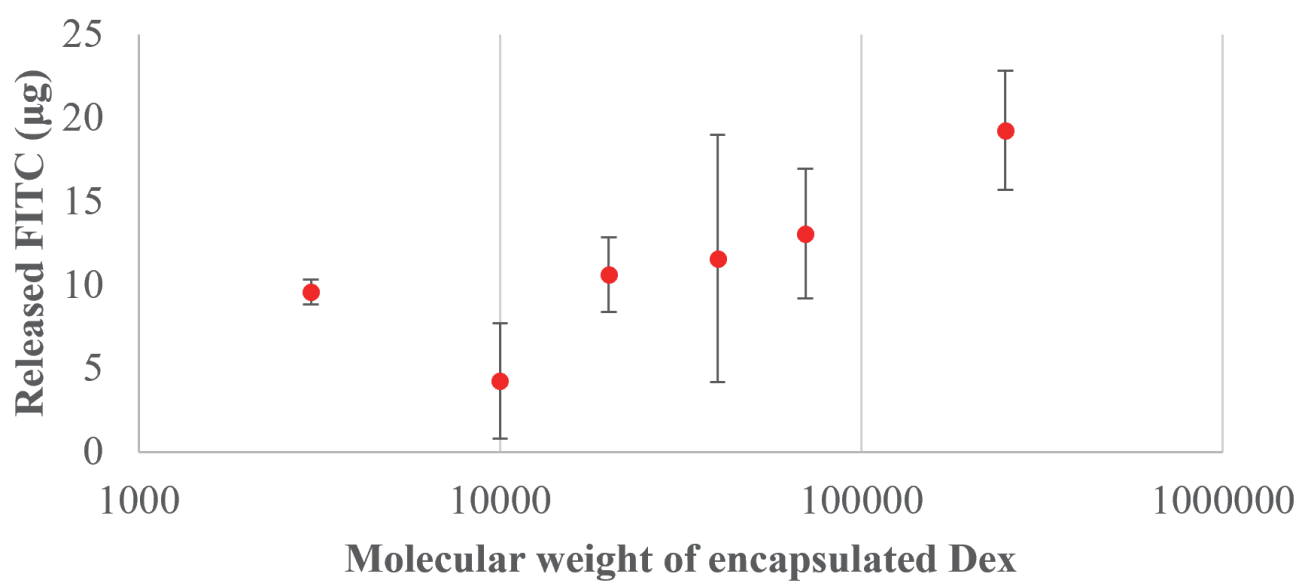

(b)

Fig. 1. (Color online) Effect of FITC-Dex molecular weight on amounts of (a) encapsulated and (b) released molecules. FITC-Dex $(1 \mathrm{mg})$ was encapsulated in each nanoparticle. After washing, the amount of FITC-Dex encapsulated in each nanoparticle was determined from its fluorescence intensity $\left(\lambda_{e x}=494 \mathrm{~nm}, \lambda_{e m}=518 \mathrm{~nm}\right)$. The nanoparticles were then UV-irradiated to release the FITC-Dex $(n=3)$.

The amount of released FITC-Dex did not directly correlate with the amount encapsulated, with $4.0-20 \mu \mathrm{g}(0.2-0.5 \%)$ of FITC-Dex released when $20-60 \mu \mathrm{g}(0.5-2 \%)$ was encapsulated in the photoresponsive nanoparticles. The molecular weight of the FITC-Dex molecules did not significantly affect the encapsulated or released amounts. These results support the conclusions drawn from the data in Table 1: the molecules are stochastically included in the mesh structure, and smaller molecules may have lower encapsulation rates.

\subsection{Effect of molecule loading on amounts of encapsulated and released molecules}

To identify the effect of the compound loading (not the molecular weight) on the amounts of compound encapsulated and released, the amount of $20 \mathrm{kDa}$ FITC-Dex added to the 
nanoparticles was varied, and the amounts of encapsulated and released FITC-Dex were examined using the FITC signal intensity. The results are shown in Fig. 2.

Particles prepared with small amounts of FITC-Dex encapsulated and released small amounts of the polysaccharide, whereas particles prepared with large amounts of FITC-Dex encapsulated and released large amounts of the polysaccharide. Hence, the amount released upon exposure to light appears to be proportional to the amount of FITC-Dex included during preparation. Nevertheless, nanoparticles with $10 \mathrm{mg}$ FITC-Dex released a lower-than-expected amount.

The particle sizes were measured before and after UV irradiation through TEM and ZetaView. The results suggested that the nanoparticles do not entirely disintegrate; rather, only part of the network structure breaks down to release the internal molecules (Figs. S5 and S6). Thus, when more molecules are encapsulated in the gel structure of the nanoparticles, the space available for molecular motion is reduced, which could hinder molecular release. This result further confirms that the molecules were stochastically distributed in the gel network structure of the nanoparticles during preparation. From these results, we believe that the encapsulation and release of several types of compounds can be tailored by controlling molecular loading during nanoparticle preparation.

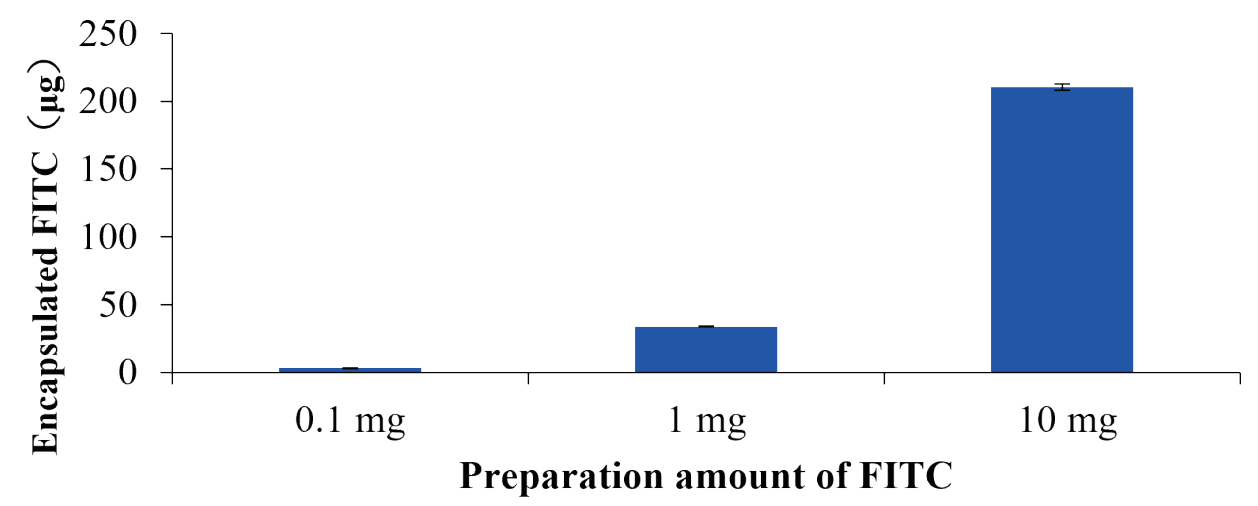

(a)

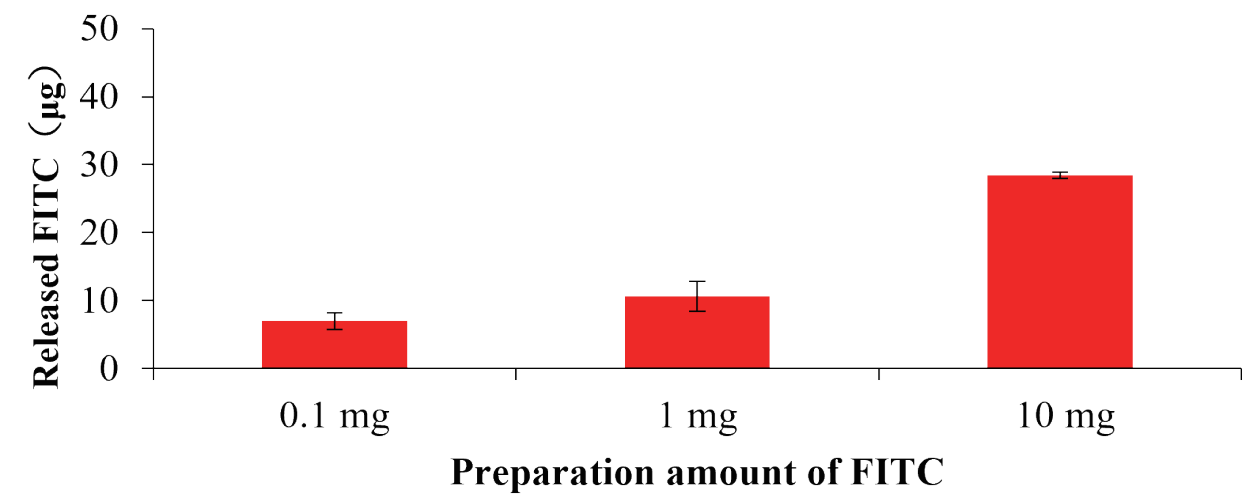

(b)

Fig. 2. (Color online) Effect of amount of FITC-Dex $(20 \mathrm{kDa})$ loaded in nanoparticles on amounts of (a) encapsulated and (b) released FITC. After washing, the amount of FITC-Dex encapsulated in each nanoparticle was determined from its fluorescence emission. Each nanoparticle was then UV-irradiated to release FITC-Dex $(n=3)$. 


\subsection{Confirming nanoparticle internalization in cells by endocytosis}

It has been reported that nanoparticles with cationic units can be introduced into cells by endocytosis; ${ }^{(10)}$ thus, we expected that the nanoparticles containing cationic linkers could also be introduced into cells. To demonstrate this, nanoparticles containing $20 \mathrm{kDa}$ FITC-Dex were added to HeLa cells treated with one of three endocytosis inhibitors (chlorpromazine, a clathrinmediated endocytosis inhibitor, methyl- $\beta$-cyclodextrin, a caveolae-mediated endocytosis inhibitor, or amiloride, a micropinocytosis inhibitor). Nanoparticle internalization was observed by fluorescence microscopy based on the FITC fluorescence. The cells treated with chlorpromazine exhibited no fluorescence, whereas the other cells exhibited fluorescence, which suggests that chlorpromazine inhibits nanoparticle internalization (Figs. 3 and S7). Thus, we confirmed that the nanoparticles were attracted to the surfaces of the HeLa cell membranes, where clathrin-mediated endocytosis introduced them into the cells.

(a)

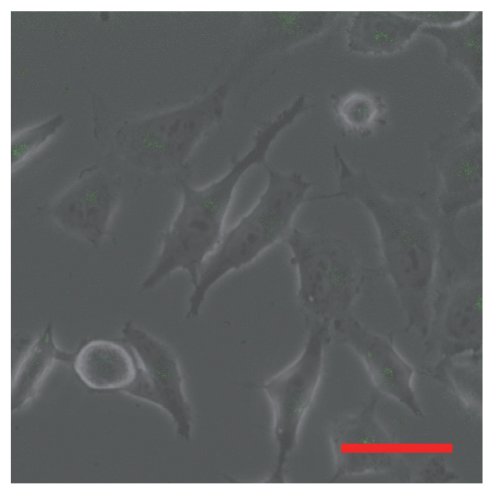

chlorpromazine

(c)

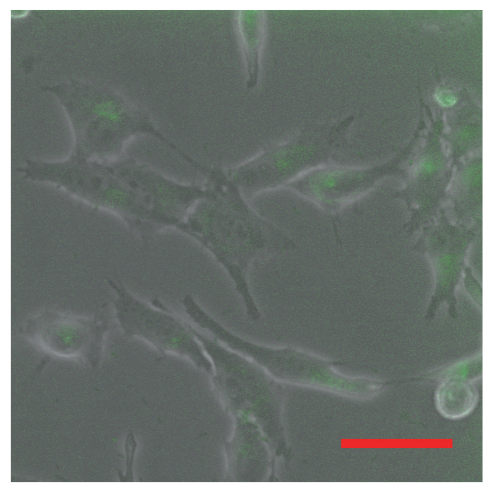

amiloride (b)
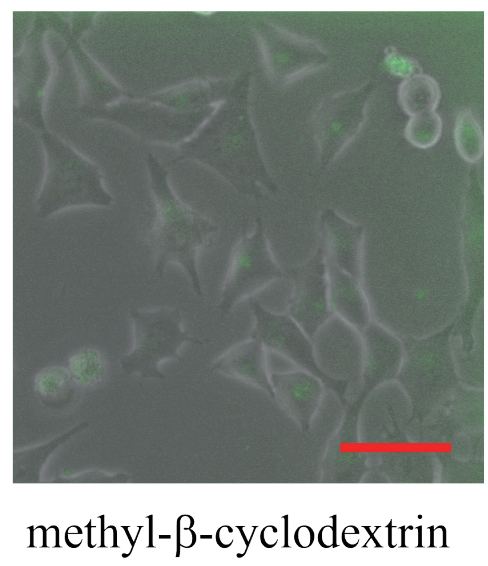

(d)

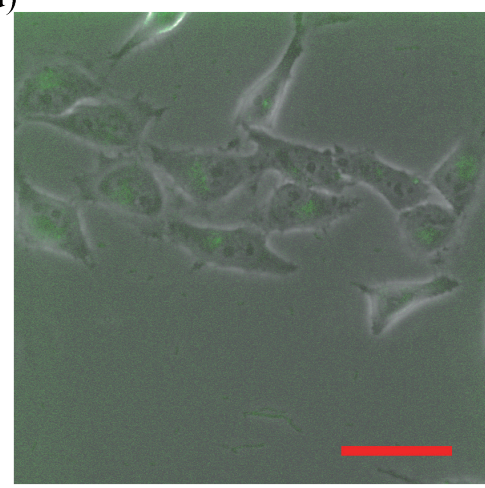

control

Fig. 3. (Color online) Merged fluorescence $\left(\lambda_{e x}=494 \mathrm{~nm}, \lambda_{e m}=518 \mathrm{~nm}\right)$ and bright-field images of cells containing nanoparticles and three endocytosis inhibitors. The nanoparticles containing FITC-Dex $(20 \mathrm{kDa})$ were added to HeLa cells with one of the following three inhibitors: (a) chlorpromazine (final $14 \mu \mathrm{M}$ ), (b) methyl- $\beta$-cyclodextrin (final $2 \mathrm{mM}$ ), or (c) amiloride (final $0.7 \mathrm{mM}$ ). (d) Control sample containing no inhibitor. The cells were observed by fluorescence microscopy after incubating for $20 \mathrm{~min}$ and washing. Scale bars: $50 \mu \mathrm{m}$. 


\subsection{Controlling in vitro enzyme activity with nanoparticles}

Typical protein molecules are similar in size to the FITC-Dex molecules examined herein. Therefore, we next investigated the encapsulation and release of proteins. Photoresponsive nanoparticles containing different amounts of the three enzymes (final concentrations of elastase, chymotrypsin, and caspase 3: 80-8000, 800-80000, and 10-100 $\mu$ unit/mL, respectively) were prepared (Table S1), and their activities following release by UV irradiation $\left(365 \mathrm{~nm}, 0.25 \mathrm{~W} / \mathrm{cm}^{2}\right)$ were determined. UV irradiation decreased the enzyme activity (Fig. S1). Figure 4 reveals that the activities of the enzymes released from the nanoparticles are in the 2.0-0.04 $\mu$ unit range and depend on the amount of enzyme used during the preparation of the gel structure; hence, the activity can be tailored by adjusting the enzyme loading within the above-mentioned ranges. The functions of the various enzymes and other types of compounds exhibiting different properties can be controlled using this nanoparticle-based method.

\subsection{Controlling in-cell protein activity with nanoparticles}

Finally, we demonstrated quantitative control over the release of caspase 3 within cells using the nanoparticle encapsulation and release method. We prepared nanoparticle solutions for the release of 0.040 and $0.090 \mu$ unit caspase 3 (nanoparticles with caspase 3: 100 and $10 \mu u n i t / m L$ ) and a control solution of nanoparticles devoid of caspase 3 ( $0.0 \mu \mathrm{unit})$. The three nanoparticle solutions were introduced into HeLa cells by endocytosis and irradiated with UV light to release the encapsulated caspase 3 , and the time-dependent cell changes were monitored by microscopy.

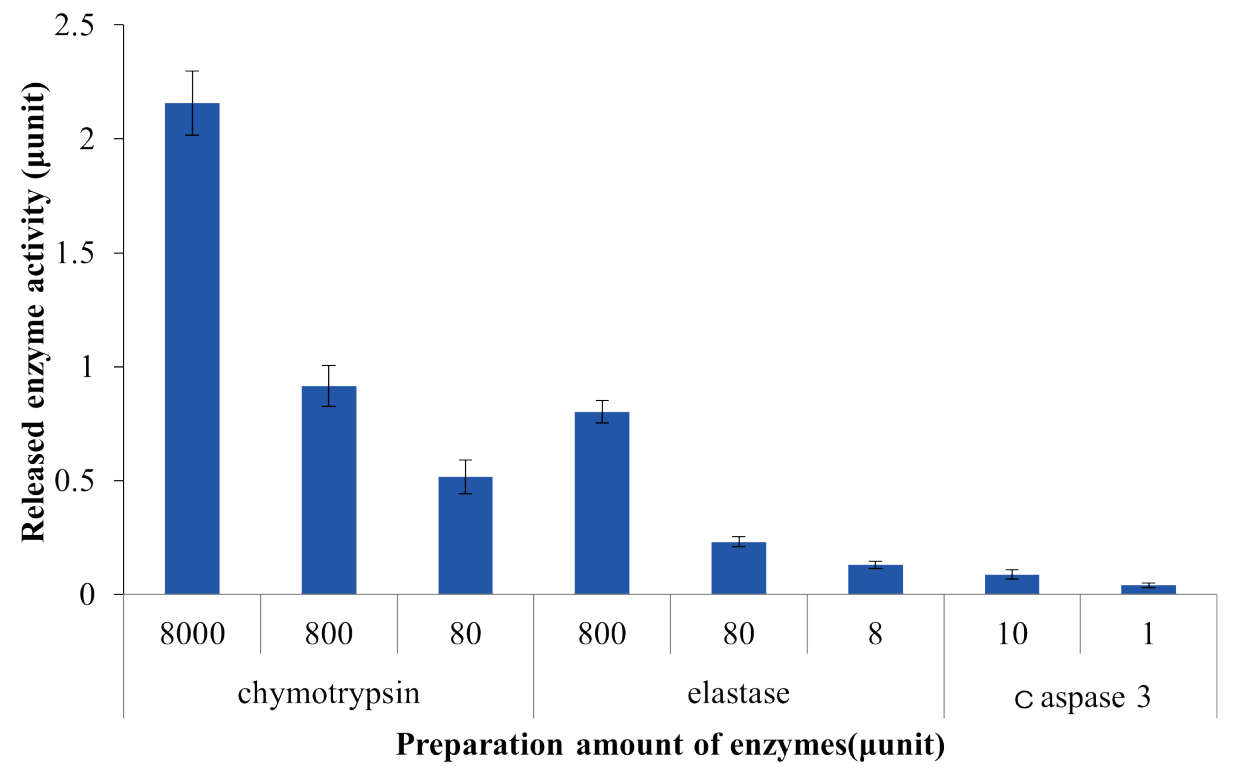

Fig. 4. (Color online) Effect of enzyme loading on released enzyme activity for three different enzymes. After washing, the enzymes were released from the nanoparticles by UV irradiation, and their activities were measured relative to that of the substrate $(n=3)$. 
Figure 5(a) shows microscopy images and enlarged images of the HeLa cells 15 min after irradiation. Several cells showed contraction when treated with the caspase-3-containing nanoparticles that released $0.90 \mu$ unit caspase 3 into the cells. In contrast, very few cells showed contraction when treated with the control nanoparticles that did not contain caspase 3. Figure 5(b) shows the survival rates of the cells in 5 min intervals after irradiation. Although almost all

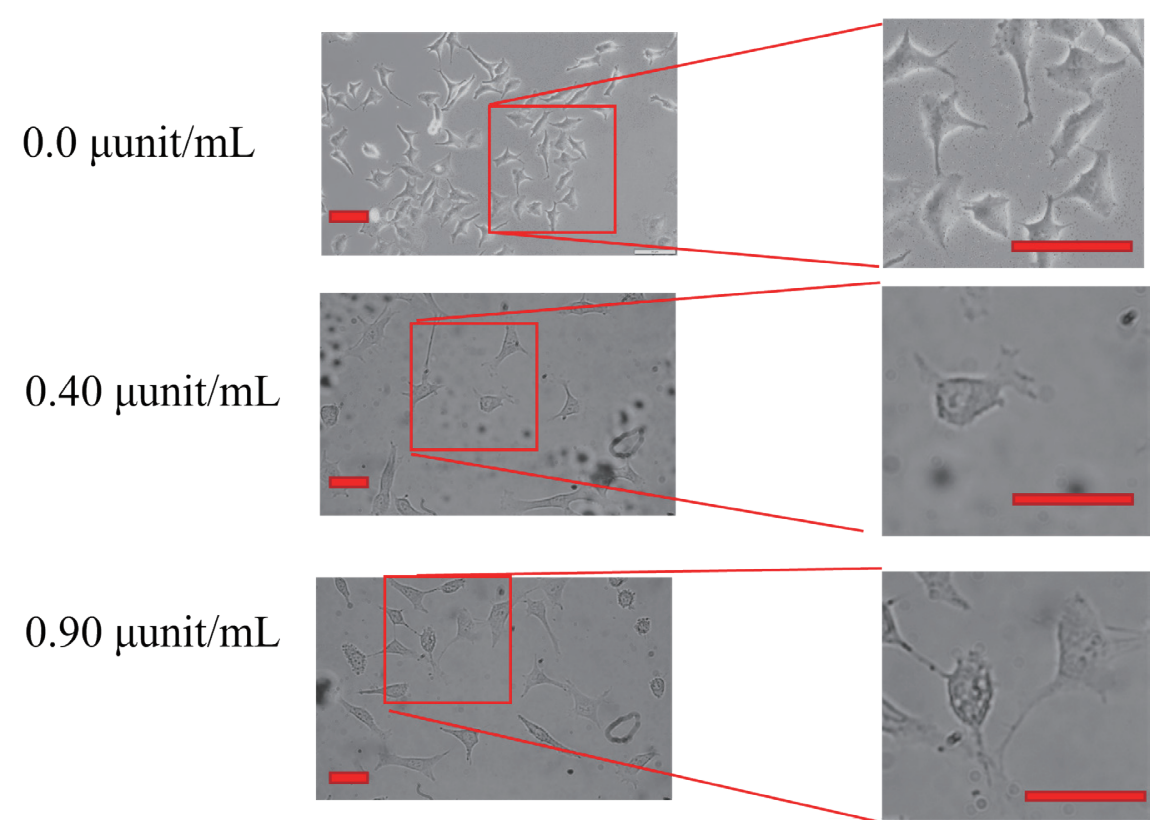

(a)

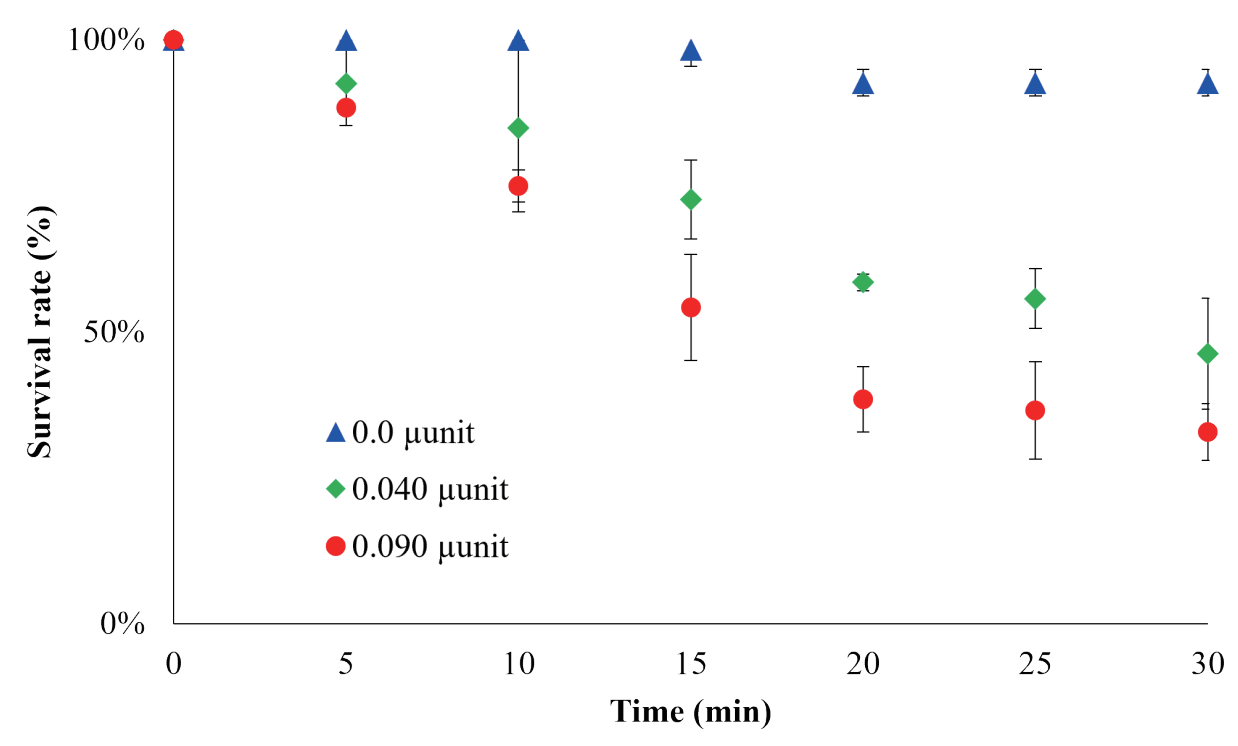

(b)

Fig. 5. (Color online) (a) Microscopy images of HeLa cells 15 min after UV irradiation. Scale bars: $50 \mu \mathrm{m}$. (b) Cell survival rates after irradiation. The nanoparticles were loaded with 0 (blue), 0.4 (green), and 0.9 (red) $\mu u n i t / \mathrm{mL}$ caspase $3(n=3)$. 
1000

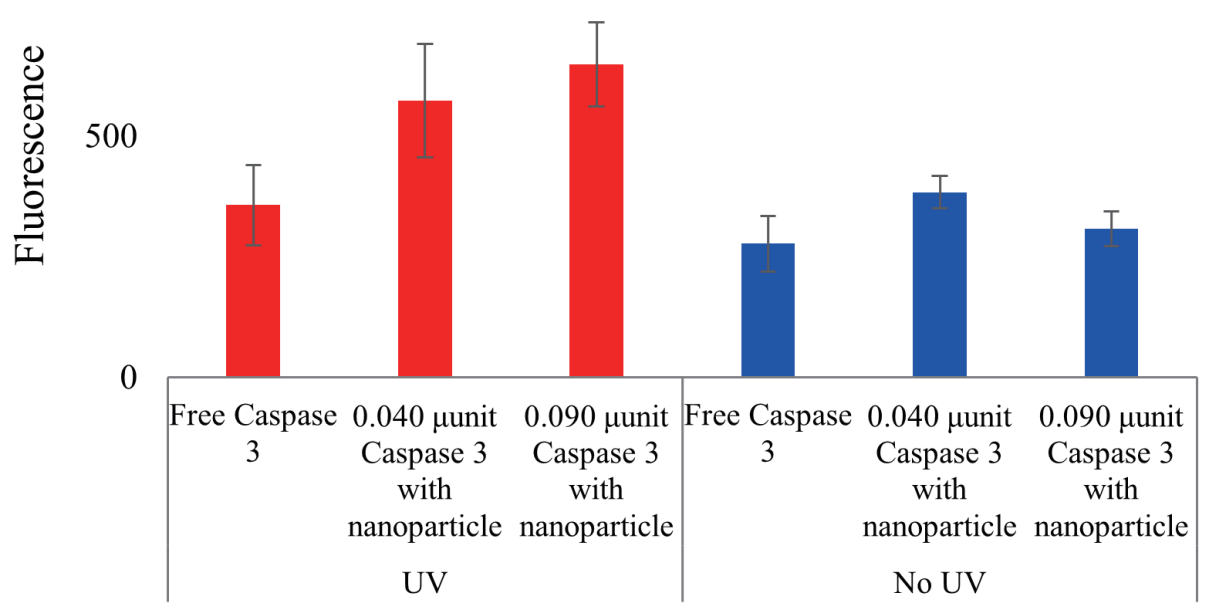

(c)

Fig. 5. (Color online) (Continued) (c) Cell death recognized by PI staining for cells with UV irradiation (red) and without UV (blue) $(n=3)$.

the cells survived for 30 min after treatment with the control nanoparticles (devoid of caspase 3), the survival rates of the cells decreased after 5 min when treated with the caspase-3-containing nanoparticles. This decrease in the survival rate is caused by the release of caspase 3 . It took approximately $25 \mathrm{~min}$ for half the cells to die when the nanoparticles were loaded with 0.40

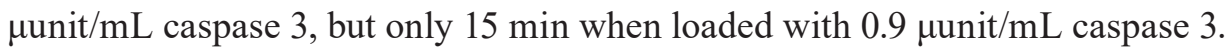

Figure 5 shows the differences in the responses of the cells. We expected the reaction to be heterogeneous because the cell sizes and cycles are not uniform, which leads to different transfection efficiencies and cell responses. ${ }^{(16)}$ This increase in cell death is supported by the fluorescence of the PI-stained samples [Fig. 5(c)].

Increasing the amount of caspase 3 released from the nanoparticles tended to reduce the time to cell death, as demonstrated in previous studies. ${ }^{(17)}$ By changing the nanoparticle preparation conditions to control the amount of protein included in the nanoparticles, we could tailor the activity of the released protein, and therefore alter the cellular response.

\section{Conclusions}

By adjusting the conditions for preparing weak cationic nanoparticles, we successfully controlled the loading of proteins encapsulated in photoresponsive nanoparticles. A mesh structure is formed during nanoparticle polymerization, which is not affected by the properties (type, size, function, etc.) of the encapsulated protein. The activity of the protein released during UV irradiation was also successfully regulated by controlling the protein loading (concentration: $0.40-20 \mu \mathrm{unit} / \mathrm{mL}$ ) in the nanoparticles. As a proof of concept, we demonstrated the ability to 
control the caspase 3 activity in cells. This is the second example in which PARCEL technology was used to control the activity of the protein released into cells. ${ }^{(12)}$ Furthermore, it was possible to deliver the amount of protein necessary for activity using this method, even for a range of protein types. Therefore, we expect that this method will be used to control the intracellular functions of many physiologically active substances. Since the PARCEL method is a highly noninvasive technique, it is expected to become a powerful tool for elucidating the detailed functions of proteins in the cytoplasm and for controlling cell functions.

\section{Acknowledgments}

This work was supported by JSPS KAKENHI (Grant Numbers 18K19413, 21K06497) and the JSPS Core-to-Core Program, A. Advanced Research Networks. We would like to thank Mr. Hiromu Kurase for help with the experiments used to obtain the results in Fig. 5.

\section{References}

1 K. Makanae, R. Kintaka, T. Makino, H. Kitano, and H. Moriya: Genome Res. 23 (2013) 300. https://doi. org/10.1101/gr.146662.112

2 H. Moriya: Mol. Biol. Cell 26 (2015) 3932. https://doi.org/10.1091/mbc.E15-07-0512

3 G. Li, D. Burkhardt, C. Gross, and J. Weissman: Cell 157 (2014) 624. https://doi.org/10.1016/j.cell.2014.02.033

4 O. Zelphati, Y. Wang, S. Kitada, J. Reed, P. Felgner, and J. Corbeil: J. Bio. Chem. 276 (2001) 35103. https://doi. org/10.1074/jbc.M104920200

5 Z. Gu, M. Yan, B. Hu, K. Joo, A. Biswas, Y. Huang, Y. Lu, P. Wang, and Y. Tang: Nano Lett. 9 (2009) 4533. https://doi.org/10.1021/n1902935b

6 N. Morimoto, S. Hirano, H. Takahashi, S. Loethen, D. Thompson, and K. Akiyoshi: Biomacromolecules 14 (2013) 56. https://doi.org/10.1021/bm301286h

7 T. Hirakura, Y. Nomura, Y. Aoyama, and K. Akiyoshi: Biomacromolecules 5 (2004) 1804. https://doi. org/10.1021/bm049860o

8 S. Murayama and M. Kato: Anal. Chem. 82 (2010) 2186. https://doi.org/10.1021/ac1003757

9 S. Murayama, B. Su, K. Okabe, A. Kishimura, K. Osada, M. Miura, T. Funatsu, K. Kataoka, and M. Kato: Chem. Commun. 48 (2012) 8380. https://doi.org/10.1039/C2CC32718J

10 S. Murayama, T. Nishiyama, K. Takagi, F. Ishizuka, T. Santa, and M. Kato: Chem. Commun. 48 (2012) 11461. https://doi.org/10.1039/C2CC35567A

11 S. Murayama, J. Jo, Y. Shibata, K. Liang, T. Santa, T. Saga, I. Aoki, and M. Kato: J. Mater. Chem. B 1 (2013) 4932. https://doi.org/10.1039/C3TB20828A

12 Y. Shibata, S. Murayama, T. Amamoto, T. Santa, and M. Kato: Appl. Spectrosc. Rev. 51 (2016) 669. https://doi. org/10.1080/05704928.2016.1167068

13 S. Murayama, F. Ishizuka, K. Takagi, H. Inoda, A. Sano, T. Santa, and M. Kato: Anal. Chem. 84 (2012) 1374. https://doi.org/10.1021/ac2023603

14 A "unit" is the amount of catalytic activity that will raise the rate of reaction by $1 \mathrm{~mol} / \mathrm{s}$ in a specified assay system. See: Nomenclature Committee of the International Union of Biochemistry (NC-IUB) "Units of Enzyme Activity" Recommendations 1978. Eur. J. Biochem. 97 (1979) 319.

15 A. Chakraborty and N. R. Jana: J. Phys. Chem. Lett. 6 (2015) 3688.

16 J. Quintart, M. Leroy-Houyet, A. Trouet, and P. Baudhuin: J. Cell Biol. 82 (1979) 644. https://doi.org/10.1083/ jcb.82.3.644

17 M. Chandrasekaran and M. Pandurangan: Biol. Trace Elem. Res. 172 (2016) 148. https://doi.org/10.1007/ s12011-015-0562-6 